\title{
O MOVIMENTO SINDICAL BRASILEIRO E A REESTRUTURAÇÃO PRODUTIVA
}

Lourival José de Oliveira *

SUMÁRIO: 1. Introdução. 2. O método propositivo de negociação. 3. As comissões de fábrica. 4. O processo de reestruturação produtiva. 5. O sindicato internacional. 6. Conclusão. 7. Bibliografia.

SUMMARY: 1. Introduction. 2. The proposal method of negotiation. 3. The Comissions' factory. 4. The restructuring process of productive. 5. The international sindical. 6.Conclusion. 7. Bibliography.

ÜBERSICHT: 1. Einführung; 2. Die Methode der Verhandlungen durch Vorschläge 3. Die Fabrikhommissionen 4. Der Prozess der produktiven Restrukturierung 5. Die internationale Gewerkschaft 6. Schlussfolgerung 7. Bibliographie.

RESUMO: O movimento sindical vem enfrentando várias dificuldades frente ao processo de reestruturação produtiva que está ocorrendo. As práticas de confronto estão dando lugar à chamada postura propositiva, introduzindo-se novas modalidades de participação do trabalhador nos destinos da empresa. Ao mesmo tempo deve participar no plano internacional, propondo a integração do local ao regional.

\footnotetext{
"Mestre em Dircito dus Rclaço Sociais/UEL. Doutor em Direito/PUC-SP. Professor do Gurso de Graduaça em Direito, do Carso de Mestrado en Direito Negocial da Universidade Estadual de Londrina. Professor da Universidude Norte do Parand-UNOPAR. Professor da Universidade Paranaense - UNIPAR.
} 


\begin{abstract}
The syndical movement is facing several difficulties front to the process of productive restructuring that is happening. The confrontation practices are giving place to the call proposal posture, being introduced new modalities of the worker's participation in the destinies of the company.
\end{abstract}

ZUSAMMENFASSUNG: Die Gewerkschaftsbewegung sieht sich verschedenen Schwierigketen angesichts der gegenwätigen produktven Restrukturierung gegenüber. Die Praxis der Konfrontation weicht der sog. Vorschlagshaltung, wobei neue Arten der Beteiligung des Arbeiters an dem Schicksal des Unternehmens eingefuhrt werden.

PALAVRAS-CHAVE: Movimento sindical. Reestruturaçäo produtiva. Participaçao do trabalhador.

KEY-WORDS: Sindical Movement. Productive restucturing. The worker's participation.

SCHLUSSELWÖRTER: Gewerkschaftsbewegung. Produktive Restrukturierung. Beteiligung der Arbeiter.

\title{
1. Introdução
}

Na decada de 90 ocorreram mudanças na direcão do movimento sindical brasileiro, passando de uma orientaça de confronto para uma orientação chamada de convergencia propositiva, não demonstrando as mesmas iniciativas politicas de antes tendo em vista que o seu pano de fundo, a democratização, perdeu sua vez para as crises do desemprego, da recessáo econômica e para as crescentes alteraçöes no novo modo de produção.

No entanto, fica claro através dos congressos de trabalhadores que se realizaram na década de 80 , em especial o IV Congresso dos Metalúrgicos de 1983 , que era necessärio estabelecer projetos que cuidassem da introduçào 
de novas tecnologias e uma política para o setor de informática que atendessem os interesses dos trabalhadores. Da mesma maneira parecia imprescindivel a organização nos locais de trabalho, através da constituição de grupos chamados comissoes de fábrica (ou outras denominaçes adotadas), da criação de subcomissóes localizadas a fim de enfrentar a reestruturaça do processo produtivo, seja negociando a introduçăo de novas tecnologias, seja participando da nova distribuição de tarefas.

Foram enfrentadas várias dificuldades dentro do próprio sindicalismo com as propostas de estruturação dessas formas de organização de base. Houve por assim dizer um verdadeiro combate às comissões de fábricas, que em algumas situaçóes passaram a ser vistas até mesmo como uma ameaça ao sindicato. Houve ainda outra prática sindical, sempre marcada pelo confronto ideológico, de resistência às alterações que ocorreriam na produçăo, mais voltadas à sustentação de partidos políticos do que propriamente às necessidades mais próximas das relações de trabalho.

\section{O método propositivo de negociaçăo}

Principalmente com o III Congresso da CUT de 1988 começaram a ocorrer concretamente as primeiras alteraçoes práticas, ganhando relevância a negociação coletiva e demonstrando claramente o contraste que surgiria com a prática passada, tendo em vista a adoção de novas técnicas conhecidas como estratégias sindicais propositivas. Segundo a socióloga Márcia de Paula Leite, a adoção da estratégia sindical propositiva seria a única saida para a crise do sindicalismo diante da reestruturaçăo produtiva, visto que resistir às mudanças ocorridas nos modos de produção seria o suicídio do sindicalismo. Adotar práticas de confronto, segundo a socióloga, é contribuir para que as práticas empresariais marginalizem mais ainda os sindicatos ${ }^{1}$.

É dotada de racionalidade a proposta apresentada pela socióloga, uma vez que os sindicatos somente manter-se-ão vivos no processo de

\footnotetext{
I LETE, 1997, p. 14.
} 
reestruturaçäo produtiva a partir do momento em que organizando-se, implantem nos locais de trabalho efetivamente as suas bases de sustentação, assumindo uma postura propositiva na defesa dos seus representados. Não se trata de aderir a uma situação. Trata-se de saber lidar, através de estratégias diferentes, com a nova realidade posta, de forma a valorizar a negociaçäo coletiva, passando por uma rápida transformaça no que tange ao aspecto político-ideológico de confrontação com o capital, e, para que isso seja alcançado, parte-se do princípio da necessidade da interiorização do movimento associativo dos trabalhadores, o qual deverá estar dentro da fábrica e nâo distante dela.

Um exemplo dessas alteraçōes sofridas no que tange às negociaçoes foi a forma tripartite de negociação, que deu como resultado o acordo com as montadoras ocorrido no periodo de 1992 a 1995 , em que os trabalhadores se colocaram preocupados com o destino da empresa onde trabalhavam, negociando uma política setorial que levasse em consideraçăo os preços dos automóveis, o mercado, os tributos cobrados, dentre outros elementos, nào se restringindo aos seus salários ou condições diretamente relacionadas com o trabalho e transfomando para alguns especialistas do assunto num marco das relaçóes trabalhistas no Brasil. A título de exemplo salienta Frederico que o acordo rompeu com o corporativismo varguista, traço dominante das relaçōes trabalhistas no país, instaurando, por assim dizer, uma nova modalidade de participação operária no processo de luta de classe, onde a presença do Estado foi somente para monitorar o acordo?2.

Diante de todas essas transformações a CUT (Central única dos Trabalhadores) lançou o novo sindicato, batizando-o de sindicato orgânico. Segundo Marcelo Sereno, integrante da articulação sindical da CUT:

A CUT defende a construção dos sindicatos orgânicos, que são sindicatos de massas, por ramo de atividade. Precisamos encarar alguns desafios. Ao invés de termos 2.500 sindicatos filiados à central, o ideal seria ter algumas dezenas de sindicatos nacionais. Nosso primeiro problema é o fato do sindicato ser muitas vezes poder em sua cidade. Um sujeito ambicioso prefere ser presidente ou

2 FRFDERICO, 1994 , p. 10 e seguintes. 
tesoureiro do sindicato e ter a chance de chegar a vereador, a ser delegado sindical ou delegado de base de um sindicato nacional, de centenas de milhares de trabalhadores filiados e capacidade muito superior de enfrentar o patronato. $O$ novo sindicato poderia enfrentar dramas de que o Dirceu Travesso falou, são verdadeiros. Além da guerra fiscal, as empresas procuram fomentar uma guerra sindical no Brasil. Oferecem vantagens aos sindicatos, acenam com propostas de qualidade e participação nos lucros. Antes de decidirem onde väo instalar uma nova fabrica, procuram comprar a docilidade dos dirigentes sindicais. Mas se o sindicato tiver um ambito que extrapola a categoria, e passar a ser um sindicato nacional de centenas de milhares de trabalhadores, a possibilidade de enfrentar esse debate com eficiencia sera muito maior. E' claro que na proposta de sindicato orgânico há alguns aspectos que talvez expressem divergências. Um deles é o fato da proposta transformar os sindicatos em instâncias da CUT (grife-se) ${ }^{3}$.

Sob os efeitos da reesmuturaçāo produtiva, o sindicalismo brasileiro apresentou suas mudanças com vistas em atender as necessidades criadas e reconhecendo a necessidade de participar das discussóes dentro da empresa. Nesse sentido, as chamadas comissöes de fábricas, em especial as do setor automotivo, rèm se desenvolvido, ampliando suas funções ao ponto de quase se constituir um sindicato dentro da empresa, opondo-se, nesse sentido, a algumas posiçóes tomadas pelos sindicatos dos metalúrgicos e acirrando ainda mais a discussảo em torno da proposta do modelo necessário de sindicalismo para enfrentar esse novo processo produtivo.

\section{As comissóes de fábrica}

As comissões de fábrica, principalmente, e outras formas não oficiais de organização de trabalhadores, entendidas genericamente enquanto movimentos associativos de trabalhadores, vêm ganhando espaço na indústria automobilística. As comissōes de fábrica, em especial, já possuem espaços próprios dentro das montadoras, e seus membros, escolhidos pela forma eletiva dentre os trabalhadores, são liberados para participar de

\footnotetext{
3 SERENO, 1997, 121.
} 
atividades político-reivindicativas, chegando até a serem as comissōes de fábrica tidas como o próprio sindicato em termos de representatividade nas negociaçoes, tratando de assuntos que vão desde brigas no ambiente de trabalho até a instauração de programas de qualificação profissional.

Esse movimento de participaçäo direta dos trabalhadores vem efetivamente ganhando força, sendo considerados pelos críticos que näo concordam com esse tipo de ação também como fator de desestruturação do sindicalismo e favorecimento do controle do movimento de trabalhadores pelos empresários no Brasil. De outra parte esquecem-se que esse tipo de translomação não vem ocorrendo somente no Brasil. A situação da Europa, guardadas as diferenças $e$ as devidas proporções, tem mostrado que a mudança estrutural enfraqueceu a coerencia interna do sindicalismo e trouxe una série de tensōes como por exemplo a desestabilização das tradicionais confederaçes sindicais, a redução da legitimidade das confederações, a competição entre sindicatos para angariar novos filiados, a criação de dierenças dentro dos sindicatos, como por exemplo, entre os empregados e desempregados, entre os qualificados e os desquailicados, aliado ao crescimento das organizaçoes não oficiais de trabalhadores dentro das Gábricas.

Em que pese a rejeicão por boa parte dos movimentos de representação direta dos trabalhadores junto à empresa no Brasil, é certo que muito mais do que antes, diante do revolucionário processo de reestruturaça produtiva, essas formas de movimento de trabalhadores poderão representar a efetiva participação do trabalhador junto a administraça empresarial, podendo ser entendida como uma das possibilidades concretas de participação do movimento de trabalhadores ante a reestruturação dos modos de produção.

\section{O processo de reestruturaçăo produtiva}

Não é possivel restringir a crise existente (precarização do trabalho, desemprego) para explicar esse chamado recuo do movimento sindical no 
Brasil. Deve-se ter em mente o que ocorreu na ordem internacional, com o desmantelamento do socialismo, materializado na queda do muro de Berlim, que deixou de ser ideologicamente visualizado um antagonismo entre o capital e o trabalho, vindo criar-se parceria dos dois, o que demonstra que novas estratégias sindicais de cooperação significa na verdade a busca de novos mecanismos de participação na produção.

O novo complexo produtivo, com novos sistemas de gerenciamento, de terceirização e de participação do trabalhador foi reproduzido enquanto um grande esforço no treinamento comportamental de gerentes, chefes, mestres, supervisores, líderes4.

Essa nova reestruturação produtiva, diferente de qualquer outra já ocorrida nos últimos séculos, impôs mudanças dentro da empresa, no que tange à adoção de novos sistemas internos de produção bem como na relação entre as empresas.

Com a chamada descentralização produtiva, caracterizada principalmente pela chamada terceirização, alterou-se significativamente o mundo do trabalho. Na medida em que se constituiu uma nova rede de produção, atendendo-se os princípios da racionalização da produção e das novas técnicas de gestão da produção (com programas de gerenciamento pela Qualidade Total), teve-se a necessidade da transferência de atividades produtivas para outras empresas, mudando conseqüentemente a concepção do chamado espaço-território da produção. Antes a terceirização atingia os serviços de apoio à produção, como limpeza, transporte, vigilância e outras. $\mathrm{Na}$ nova reestruturação produtiva atingiu diretamente as atividades vinculadas aos setores principais de produção, com trabalho qualificado, oferecendo uma nova divisão do processo produtivo aliado à manutenção do nível tecnológico. No caso do setor automotivo, aqui tomado como exemplo de reestruturação, as montadoras devem apenas fiscalizar a produção e não produzir ou mesmo montar os seus veículos, visto que a montagem de automóveis (Ford, VW, General Motors) está sendo realizada por empresas

\footnotetext{
4 Sobre o tema ver: Boletins DIEESE, novenbro de 1994 e março de 1995, respectivamente Trabalho e Reestruturaçäo Produliva - 10 anos de linha de produçâo e A reestruturaçăo negociada na Industria Automobilística Brasileira".
} 
contratadas no espaço cedido pela própria montadora, passando as mesmas a se constituírem em organizações de marketing de vendas. As montadoras cederam espaço e equipamento para que os fomecedores operem internamente, ou seja, em sua própria fábrica, ocorrendo o chamado consórcio modular ou condomínio industrials.

Dessa maneira, essa nova terceirização não vai desenvolver apenas uma nova forma de subordinação ligada que está agora aos interesses da corporação e não mais somente aos da empresa. Cria-se um novo trabalhador, vinculado a um mundo do trabalho diferente, transformando o coletivo do trabalho principalmente através da chamada desconcentração operária.

\section{O sindicalismo internacional}

Para coordenar as negociaçöes nos limites das grandes corporaçóes ou trabalhar outros espaços do desenvolvimento economico deve-se pensar nas organizaçóes transnacionais de trabalhadores. No entanto, antes de qualquer referencia a essa forma de organização impoe-se realizar alguns estudos sobre a negociação coletiva enquanto instrumento de integração.

A negociaçăo coletiva local ou nacional acaba sendo afetada pelo processo de integração ou, ainda que o Estado não faça parte de um mercado comum, poderá sofrer os efeitos de fenômenos externos, como foi o caso do exemplo citado da "GM" - americana em relação à "GM" do Brasil. Dessa maneira, observa-se que existe no caso uma dialética, onde a negociaçăo coletiva poderá solrer os efeitos de fatores extemos e ao mesmo tempo se constituirá um instrumento de integração laboral ${ }^{6}$.

Observa-se dessa maneira que a negociação coletiva é fator primordial. para a integraça laboral. Não se quer com isso desprezar as iniciativas estatais como, por exemplo, convençoes ou tratados intemacionais sobre

\footnotetext{
5 ALVS, 1998 , p. 128 e segunes

6 URIARTE, 1996, p. $73 \% 4$.
} 
matéria laboral ou mesmo previdenciária, ainda que se entenda que a realizaça destes instrumentos internacionais nasçam do anseio de uma comunidade, que é revelada e traduzida pelo poder político. o que se quer afimar é a importância da negociação, podendo fazer surgir o acordo ou a convença coletiva de trabalho enquanto produtos que năo provem diretamente do Estado.

A negociação coletiva poderá gerar alguns efeitos importantes para o processo de integração labotal. Dentre eles vale citar a aproximaçäo das legislações nacionais, uma regulação comunitária unificada nos países que fazem parte de um determinado bloco económico, a descentralização das negociaçōes, deixando a proteção estatal, gerando o nascimento de uma negociação coletiva regional ou multinacional?

Nacla obstante, para que isso aconteça depender-se-á dos sujeitos das negociaçoes. Necessita-se da criação ou aperfeiçoamento de procedimentos ou entes transnacionais de representação dos trabahadores. Melhor dizendo, devem ser determinados os sujeitos dessas negociaçoes, sem os quais, não poderão oconrer as negociações.

Para o caso do Mercosul existe a chamada Coordenação das Centrais Sindicais do Cone Sul. Afirma Edésio Passos:

A auaçăo das entidades sindicais no âmbito do MERCOSUL tem sido intensa desde a discussão do tratado. No $4^{\circ}$ Congresso Nacional da Central unica dos Trabahadores (CUT), realizado em Sảo Paulo de 04 a 08 de setembro de 1991, foi aprovada resoluça de ampla ativiada perante 0 MERCOSUL, inclusive com a realizaçâo de encontros e seminários do então coletivo sindical formado pela CUT-Brasil PI?CNT - Uruguai, CUTParaguai e sindicatos argentinos, embriäo do que hoje se denomina de Coondenadoria de Centrais Sindicais do Cone Sul integrado pela CGTArgentina, COB-Bolivia, CGI-Brasil, Força Sindical-Brasil, CU1-Chile, CUT-Paraguai e PIT/CNT-Uruguai, apoiada pela entidade sindical internacional CIOSL-ORIT.

7 URIARTE, 1996, 13.74. 
A ação sindical no MERCOSUL de 91 até os dias atuais se ampliou $e$ aprofundou, atingindo vârias categorias profissionais dos quatro paises, integrantes de organismos de açäo conjunta na defesa dos interesses especificos de seus representados e de questöes gerais dos trabalhadores, unidas na ação coordenada pelas Centrais Sindicais, ORIT e CIOSL:.

Em que pese todo o empenho havido, segundo o mesmo autor, foi extraido das entidades sindicais um manifesto onde afirmaram: até o momento nossas propostas não tem sido ouvidas e o processo de integração continua orientado por exigências exclusivamente comerciais, em prejuizo dos critérios sociais que devem orientar prioritariamente as politicas de construção do MERCOSUL."

Com fundamento no próprio manifesto das Centrais Sindicais envolvidas no MERCOSUL é possível que as ações sindicais até o momento realizadas não tenham obtido o resultado suficiente.

Respeitadas as diferenças existentes, não tem sido muito diferente no caso da Comunidade Econômica Européia, que avançou no que diz respeito às relações comerciais sem o mesmo desenvolvimento no que diz respeito à integração do mercado de trabalho, em que pese encontrar-se em outro estágio em termos de relações laborais.

É possivel afirmar que existe a necessidade do aperfeiçoamento das açōes, coordenação das organizaçōes sindicais supranacionais, visto que, ao mesmo tempo, isso servirá de base para sustentação das negociaçōes locais e nacionais. E estas, por sua vez, de base para aquelas.

Observa-se que existe um todo integrado. As organizações de base irão refletir o que de fato deve ser compreendido como anseio dos trabalhadores. Nesta mesma base já existirá a integração dentro da empresa e com outros núcleos de outras empresas, de acordo com o nível de vinculaçăo de determinada atividade econômica. A integração começará na base. Compondo a estrutura sindical, aparecerão os entes externos de organização, local, nacional e regional. Todos também coordenados, uma vez que ao

\footnotetext{
8 PASSOS, 1999 , p. 11.

9 MSSOS, 1999, p. 12
} 
mesmo tempo as negociacóes locais e nacionais daräo suporte para as negociaços supranacionais e estas para as locais e nacionais. Foi encontrado o processo dialético, o ir e vir, a ação e a contradiça, tudo sendo colocado ao mesmo tempo, como sustentáculo da negociação que, apesar de divisivel, de acordo com as especificidades de determinada atividade economica, é uma negociação única, em plena sintonia com o contexto social em que está imersa, ao mesmo tempo homogênea e heterogenea.

Acompanhando toda essa dialética vem a ligação das onganizaçoes de trabalhadores com outros movimentos ou organizaçes populares, partindo essa interaçăo da base até as formas supranacionais. Trata-se da descompantimentaça da discussäo laboral, visto que näo mais existe uma discussão de trabalhadores com trabalhadores. Os interesses defendidos são sociais, não mais pertencendo somente ao âmbito da empresa. Da mesma maneira, näo prepondera mais como interesse maior o interesse do trabalhador, uma vez que foi suplantado pelo interesse de toda uma comunidade, sendo aquele parte deste, constituindo essa comunidade o todo.

Observa-se que näo mals prevalece no ápice, como um dos principais principios do direito do trabalho, a proteça do hipossuficiente, entendendo-se como tal somente o trabalhador. O hipossuficiente será o trabalhador com emprego e o trabalhador sem emprego, ou seja, o conjunto de toda a sociedade, tendo em vista a crise social que é provocada tanto pelo desemprego como pelo aumento dos custos de uma produção, que por certo relletirá no valor do produto final produzido, e consequentemente na viabilidade ou näo de produção em determinado ramo de atividade econômica, considerando-se a competição existente. Fm uma negociaçăo supranacional, devem evitar exemplos como o ocorrido na industria automobilistica onde o veículo produzido na Argentina influenciou na geração do desemprego na indústria automobilistica sediada no Brasil. E' nesse momento que se torna importante a negociaçao supranacional, ou regionalizada, no caso da existência de blocos economicos como forma de buscar o equilibrio social e ao mesmo tempo o não-tratamento da força de trabalho como uma simples mercadoria. O referencial local, ainda que diante 
do fenomeno da globalização, năo pode ser perdido e a reestruturação das organizaçoes de trabalhadores devem partir de baixo para cima. Da base para as estruturas supranacionais, e destas para a base, formando um todo integrado.

\section{Conclusão}

As mudanças ocorridas no modo de produção fez com que o movimento sindical tivesse que reavaliar as práticas sindicais utilizadas. $O$ trabalhador deverá a cada dia aumentar sua participaçäo no gerenciamento empresarial, fazendo com que os órgãos sindicais se modernizem através da introdução de novas práticas que são chamadas de propositivas, as quais se distanciam do modelo ideológico empregado, que é caracterizado pela oposição entre capital e trabalho, de forma a estabelecer uma nova equação, dando-se relevância aos elementos comuns e de integração, envolvendo toda a sociedade, nacional e internacional.

\section{BIBLIOGRAFLA}

ALVES, Giommi, Reestruturaçẫo produtiva e crise do sindicalismo no Brasil. Campinas, 1998. Tese (Doutorado) - Departamento de Ciências Humanas, Universidade Estadual de Campinas.

ANTUNES, Ricardo. O novo sindicalismo no Brasil. In: CANO, Wison (Coord.). Dilemas da atualidade, 2 ed. Campinas: Fontes, 1995, p. $45-50$.

FREDERICO, Celso. Crise do socialismo e movimento operário. Sào Paulo: Contez, 1994.

FRETAS JR, Antovio Rocrigues. O direito do trabalho es desalios do próximo milenio [on line]. Disponivel na intenet via htep:/www,teiajuridica com/actj. Arquivo capturado em maio de 1999.

LETE: Marcia de Bada Recstuturaçăo produtiva e sindicatos: o paradoxo da modernidade. In: LEITE, Márcia do Paula (org.). O trabalho en movimento: reestruturação produtiva e sindicatos no Brasil. Canpinas: Papirts, 1997.

PASs05. Edêsio. I - STF garante cláusulas de convençoes coletivas; II- MERCOSUL - Relaçes de Trabalho, sindicalismo a Integração Latino Americana. Suplemento Trabalhista, Săo paulo, y 2, n.99, p.09-13, 1999 .

SERENO, Marcelo. A hora do sindicato orgänico. In: CANO, Wilson. Dilemas da atualidade: globalizaça, neoliberalismo, crise do Estado, reestruturaçáo produtiva, questâo agrária e desafios do sindicalismo. Săo Paulo: Centro de Estudos sindicais, 1997, p. 119-123.

URIARTE, Oscar Emida, Mercosul y derecho laboral. Montevidéu: Fundacion de Cultum Universitária, 1996. 